\title{
DETERMINING WEIGHTS OF FUZZY ATTRIBUTES FOR MULTI-ATTRIBUTE DECISION-MAKING PROBLEMS BASED ON CONSENSUS OF EXPERT OPINIONS
}

\author{
Seyed Hossein RAZAVI HAJIAGHA ${ }^{\mathrm{a}}$, Hannan Amoozad MAHDIRAJI ${ }^{\mathrm{b}}$, \\ Shide Sadat HASHEMI ${ }^{c}$, Zenonas TURSKIS ${ }^{\mathrm{d}}$ \\ ${ }^{a}$ Department of Management, Khatam Institute of Higher Education, Tehran, Iran \\ ${ }^{b}$ Faculty of Management, University of Tehran, Tehran, Iran \\ ${ }^{c}$ Faculty of Management, Allameh Tabatabaei University, Tehran, Iran \\ ${ }^{d}$ Faculty of Civil Engineering, Vilnius Gediminas Technical University, \\ Sauletekio al. 11, LT-10223 Vilnius, Lithuania
}

Received 24 March 2015; accepted 02 June 2015

\begin{abstract}
An important objective of a group decision-making problem is to determine the weights of attributes that are given by experts participating in the decision-making process. Since different decision-makers have unequal importance in decision-making, a series of studies focused on finding a set of appropriate weights for experts participating in a decision problem. In this paper, the problem of weight determination among decision-makers is investigated by extending an algorithm taken from the technique for order preference by similarity-to-ideal solution. In this case, a pair of most compromising and least compromising solutions is derived from individual judgments of decision-makers and then, these solutions are applied as the bases for determining the magnitude of individual alignment with the group opinion by using a closeness coefficient approach. Determining the weights of decision-makers, the group decision-making problem is then solved. Application of the proposed method is illustrated by a numerical example for the selection of a maintenance strategy.
\end{abstract}

Keywords: weights, multi-attribute, fuzzy, group decision-making, linguistic variable, triangular fuzzy number, most compromising solution, least compromising solution.

JEL Classification: C25, C51, C61, C63, D79.

\section{Introduction}

Decision-making is an intrinsic part of our daily life. From a professional viewpoint, decision-making problems can be classified into two main groups of selection and planning problems. On the other hand, most of the decisions are made considering the set of criteria

Corresponding author Zenonas Turskis

E-mail: zenonas.turskis@vgtu.lt 
that are usually conflicting. The problem of decision-making with multi-criteria is the subject of multi-criteria decision-making (MCDM). MCDM is further composed of multiple attribute decision-making (MADM) and multiple objective decision-making (MODM) (Xu 2015). MADM is used to solve selection type (discrete optimization) problems and MODM - for solving planning type (continuous optimization) problems. Multi-attribute decision-making, also known as multi-objective decision-making with finite alternatives, is an important component of modern decision science.

A great deal of research and publications is devoted to MADM problems. Hwang and Yoon (1981), Venkata (2013), Ishizaka and Nemery (2013), Zavadskas, Turskis (2011), Zavadskas et al. (2014a, 2014b) provided a complete survey and systematic classification of MADM techniques. Generally speaking, an MADM problem can be defined as follows: Let $A=\left\{A_{1}, A_{2}, \ldots, A_{m}\right\}$ be a non-empty and finite set of decision alternatives and $\left\{C_{1}, C_{2}, \ldots, C_{n}\right\}$ is a finite set of goals, attributes or criteria, according to which desirability of an alternative is to be judged. The aim of MADM is to determine a preferable alternative with the highest degree of desirability with respect to all relevant goals (Zimmerman 1987). An MADM problem can be stated in form of a $m \times n$ decision matrix $X=\left[x_{i j}\right]$, where $x_{i j}$ presents the performance of preference of the alternative $A_{i}$ of the attribute $C_{j}$, and the weight vector $W=\left(w_{1}, w_{2}, \ldots, w_{n}\right)$ which determines the importance of attributes. Multi-person decision-making, which occurs whenever two or more people actively participate in decision-making, is a ubiquitous human activity. Indeed, even when making decisions on our own, in which case decisions are not multi-person in the strict sense, we should almost always consider the situations and values of others.

Most of multi-person multi-attribute decision-making problems depend to class (4) (Fig. 1).

Condorcet (1785) specified a three-candidate profile with a majority candidate that would lose under every Borda-type method that assigns more points to a first choice than a second choice, and more points to a second than a third choice. One of the most important advances in the theory of elections and social choice during the past century was Arrow's discovery (Arrow 1950; Visco 2014) that a few appealing attributes for social ranking methods are mutually incompatible. Its essential idea is that the problems that arise from the Condorcet's paradox of voting or cyclical majorities cannot be avoided under any reasonable generalization of majority comparisons. Bellman and Zadeh (1970) offered the basis for hundreds of options for subsequent modelling of individual decisions in fuzzy environments. For multi-person decision-making models, the origins are more diverse.

Extensions of the basic model by Bellman and Zadeh can primarily be conceived in three directions:

1. Rather than a single decision-maker, there are several decision-makers involved.

2. The preference or utility function is no single valued but rather vector valued. This extension is considered in multi-attribute utility theory and in multiattribute analysis.

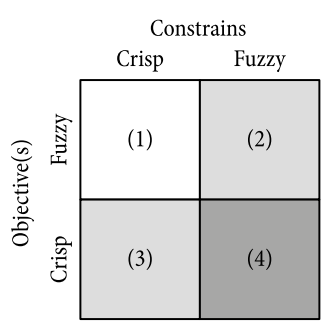

Fig. 1. Classification of fuzzy optimization problems (adopted from Leung 1988) 
3. Finally, more than the occurrence of the states is uncertain, the uncertainty of the occurrence cannot be modelled by single valued probabilities, the uncertainties are not of a probabilistic nature, or evidences for the assumptions are contradictory or insufficient.

In fact, while the complexity of social, economic, and technological world is increasing, it becomes more and more difficult for a single decision-maker (DM) to make decisions (Hwang, Lin 1986). In many real-life situations, decision-makers are interested in the value of a physical quantity that is difficult (or even impossible) to measure directly. Since we cannot measure such quantities directly, they get measured indirectly, by measuring some other quantities and using the known relations (Kreinovich 2014).

The problem become challenging once the second issue of uncertainty becomes inevitable. Yovits (1984) believed that uncertainty is a consequence of partial or approximate information. To deal with vagueness of human thought, Zadeh (1965) first introduced the fuzzy set theory, which was focused on the rationality of uncertainty due to imprecision or vagueness. Application of the framework of fuzzy optimization proposed by Bellman and Zadeh (1970) shows that the equilibrium problem in a fuzzy environment leads to the main result of fuzzy optimization which is an extremum problem of a scalar function.

A common solution approach is to reformulate the basic fuzzy optimization problem into a conventional optimization problem and then solve it by well-established algorithms (Zimmermann 1976, 1991).

Considering these two points, the main problem of this paper can be called fuzzy multi-attribute group decision-making (FMAGDM) (Kahraman et al. 2007).

FMAGDM problem has been studied previously and several methods have been proposed by researchers. Chen (2000) presented a study on extensions of the TOPSIS for group decision-making in a fuzzy environment; Turskis and Zavadskas (2010) presented a new fuzzy additive ratio assessment method (ARAS-F), which was applied for group decision-making process in order to select the location for a logistics centre; Chaudhuri et al. (2013) applied a group decision-making approach using numeric and linguistic data to solve a problem of risk assessment during the development of a new product; Xu et al. (2013) applied the Logarithmic least squares method to priority for group decision-making with incomplete fuzzy preference relations; Zhou et al. (2013) presented Generalized Multiple Averaging Operators and applied them to a group decision-making problem; Devi and Yadav (2013) presented a multi-attribute intuitionistic fuzzy group decision-making model for the selection of the location for a plant with ELECTRE method; Keršuliene and Turskis (2014) presented a hybrid linguistic fuzzy multiple criteria group selection of a chief accounting officer, which is based on ARAS-F and AHP methods; Yue (2014a, 2014b) presented and applied models of group decision-making based on aggregating interval data into interval-valued intuitionistic fuzzy information and aggregating crisp values into intuitionistic fuzzy number for group decision-making.

Most of the presented algorithms for FMAGDM problems start by initially determining individual decision-maker preferences in the form of individual decision matrices and aggregating them into a single decision-making matrix. This aggregation is done often by 
using simple or weighted arithmetic or geometric averaging operators, where a weight is assigned to each decision-maker (Hwang, Lin 1986).

Here, an issue under the question is whether to consider different decision-maker opinions on attributes as equally important or to assign different weights to them due to different expertise about each attribute. In fact, since different decision-makers have different specialty, their judgments of different attributes must be considered non-similar. Next, a prior weight for each decision-maker has to be determined; and then, individual decision matrices have to be aggregated based on these weights in an aggregated decision matrix. Ramanathan and Ganesh (1994) proposed, and later, Jabeur and Martel (2002) exploited the idea by Zeleny (1982) to determine the relative importance coefficient of each DM by using AHP method (Analytic Hierarchy Process (Saaty 1980; Saaty, Peniwati 2008)). Jabeur et al. (2004) proposed a two-step algorithm for aggregation of experts' opinions. Chen and Fan (2007) extended a factor score method (FAM) for ranking of the assessment levels of experts. Yue (2011a) presented a new approach for determining weights of DMs in the group decision environment based on an extended TOPSIS method. Yue (2011b, 2012a, 2012b) extended the TOPSIS-based method to determine weights of decision-makers, when decision matrices are expressed in interval numbers. Yue (2011c) extended his TOPSIS-based method for determining weights of decision-makers for cases when DMs preferences are expressed in interval-valued intuitionistic fuzzy information. Yue (2012c) used the projection method to determine the weights of individuals by the projection of individual decisions on the ideal solution. In his studies, Yue defined the average of decision-makers as a positive ideal solution. Dong and Saaty (2014) developed an AHP-based method that allowed decision-makers to update their judgments in each step to reach the highest consensus. Li and Chen (2014) investigated a TOPSIS-based method on the prospect theory and trapezoidal intuitionistic fuzzy numbers for group decision-making. They found weights of decision-makers by using distance measures and the trapezoidal intuitionistic fuzzy weighted averaging operator.

One common approach in the aforementioned researches is to calculate weights of different decision-makers based on closeness coefficient, as defined in TOPSIS method, as the ratio of their distance from negative ideal solution, divided by the sum of distances to negative and positive solutions. A common way of defining a positive ideal solution is considering it as the average of decision-maker preferences.

The aim of this paper is to develop a method to derive decision-maker weights, when DMs opinions are expressed in the form of fuzzy numbers. An advantage of the proposed method is to compute different weights for each decision-maker in different attributes. Suppose that $k$ decision-makers participated in a decision-making process. Usually a weight vector $\lambda=\left(\lambda_{1}, \lambda_{2}, \ldots, \lambda_{k}\right)$ is computed, where $\lambda_{l}$ is the weight of $l^{\text {th }}$ decision-maker. In this paper, a $k \times n$ weight matrix $\lambda=\left[\lambda_{l j}\right]$ is computed, where $\lambda_{l j}$ is the weight of $l^{\text {th }}$ decision-maker in $j^{\text {th }}$ attributed. The main idea of the method proposed in this paper is to find the most compromising and the least compromising solution and then define a closeness coefficient for each decision-maker to approximate decision-maker weights. These weights are then used to construct the aggregated decision matrix that implied the higher consensus among decision-makers. 


\section{Preliminaries of fuzzy set theory}

Fuzzy set theory was introduced by Zadeh (1965) and has been further developed and applied in a wide variety of practical problems. A fuzzy set $\tilde{A}$ in the universe $X$ is characterised by its membership function $\mu_{\tilde{A}}: X \rightarrow[0,1]$, where $\mu_{\tilde{A}}(x), x \in X$ denotes the membership degree of $x$ to $\tilde{A}$.

A fuzzy number is a fuzzy set $\tilde{a}$ on the real line $R$ whose membership function $\mu_{\tilde{a}}$ is a convex, upper semi-continuous function. A triangular fuzzy number (TFN) is denoted by $\tilde{a}=\left(a_{1}, a_{2}, a_{3}\right), a_{1} \leq a_{2} \leq a_{3}$, the membership function of which is as follows (Kaufman, Gupta 1991):

$$
\mu_{\tilde{a}}(x)=\left\{\begin{array}{ll}
\left(x-a_{1}\right) /\left(a_{2}-a_{1}\right), & \text { if } a_{1} \leq x \leq a_{2} \\
1, & \text { if } x=a_{2} \\
\left(a_{3}-x\right) /\left(a_{3}-a_{2}\right), & \text { if } a_{2} \leq x \leq a_{3}
\end{array} .\right.
$$

$\tilde{a}=\left(a_{1}, a_{2}, a_{3}\right)$ is defined as a positive TFN if $a_{1} \geq 0$. If $\tilde{a}=\left(a_{1}, a_{2}, a_{3}\right)$ and $\tilde{b}=\left(b_{1}, b_{2}, b_{3}\right)$ be two positive TFNs, then their arithmetic operations will be defined as follow:

$$
\begin{gathered}
\tilde{a}+\tilde{b}=\left(a_{1}+b_{1}, a_{2}+b_{2}, a_{3}+b_{3}\right) ; \\
\tilde{a}-\tilde{b}=\left(a_{1}-b_{3}, a_{2}-b_{2}, a_{3}-b_{1}\right) ; \\
\lambda \tilde{a}=\left(\lambda a_{1}, \lambda a_{2}, \lambda a_{3}\right), \lambda \geq 0 .
\end{gathered}
$$

Multiplication of two positive TFNs is not exactly a TFN, but is approximated as:

$$
\tilde{a} \cdot \tilde{b}=\left(a_{1} b_{1}, a_{2} b_{2}, a_{3} b_{3}\right) \text {. }
$$

The Euclidean distance between two TFNs $\tilde{a}$ and $\tilde{b}$ is defined as:

$$
D(\tilde{a}, \tilde{b})=\sqrt{\frac{1}{3}\left[\left(a_{1}-b_{1}\right)^{2}+\left(a_{2}-b_{2}\right)^{2}+\left(a_{3}-b_{3}\right)^{2}\right]} .
$$

\section{Fuzzy Multi-Attribute Group Decision-Making}

The FMAGDM problem is defined as follows: suppose that a group of $k$ decision-makers $\left\{E_{1}, E_{2}, \ldots, E_{k}\right\}$ are participating in a group decision-making problem. The decision problem is to compare a set of finite alternatives $\left\{A_{1}, A_{2}, \ldots, A_{m}\right\}$ to rank or to prioritise them. These alternatives are evaluated based on a set of attributes $\left(s_{j}, \alpha_{j}\right)=(s, \alpha)$. Initially, each member of the group expresses her/his preferences in the form of a decision matrix $X^{(l)}$ :

$$
X^{(l)}=\left[\begin{array}{cccc}
\tilde{x}_{11}^{(l)} & \tilde{x}_{12}^{(l)} & \ldots & \tilde{x}_{1 n}^{(l)} \\
\tilde{x}_{21}^{(l)} & \tilde{x}_{22}^{(l)} & \ldots & \tilde{x}_{2 n}^{(l)} \\
\vdots & \vdots & \ddots & \vdots \\
\tilde{x}_{m 1}^{(l)} & \tilde{x}_{m 2}^{(l)} & \ldots & \tilde{x}_{m n}^{(l)}
\end{array}\right],
$$

where $\tilde{x}_{i j}^{(l)}=\left(x_{1 i j}^{(l)}, x_{2 i j}^{(l)}, x_{3 i j}^{(l)}\right)$ is the preference of the $l^{\text {th }}$ decision-maker over the perfor- 
mance of the alternative $A_{i}$ with respect to the attribute $C_{j}$. The aim of the paper is to find a decision-makers' weight matrix $\lambda$,

$$
\lambda=\left[\begin{array}{cccc}
\lambda_{11} & \lambda_{12} & \cdots & \lambda_{1 n} \\
\lambda_{21} & \lambda_{22} & \cdots & \lambda_{2 n} \\
\vdots & \vdots & & \vdots \\
\lambda_{k 1} & \lambda_{k 1} & \cdots & \lambda_{k n}
\end{array}\right],
$$

where $\lambda_{l j}$ is the weight of decision-maker $l$ opinion about attribute $j, \lambda_{l j} \geq 0$, $l=1,2, \ldots, k ; j=1,2, \ldots, n$ and for each $j=1,2, \ldots, n, \sum_{l=1}^{k} \lambda_{l j}=1$. Finally, the aggregated decision matrix $D=\left[\tilde{x}_{i j}\right]$ is obtained, where $\tilde{x}_{i j}=\sum_{l=1}^{k} \lambda_{l j} \tilde{x}_{i j}^{(k)}$.

\section{Fuzzy Multi Attribute Group Decision-Making Approach}

The proposed algorithm for solving FMAGDM problem consists of three main stages: Initialization, Aggregation, and Final Ranking.

\section{Initialization}

First of all, the alternative set $A$ and attributes set $C$ are determined. Then, the decision-making team including $k$ experts or decision-makers (DMs) is formed. Each expert states his or her individual decision matrix $X^{(l)}=\left[x_{i j}^{(l)}\right], l=1,2, \ldots, k$ along with individual weight vector $W^{(l)}=\left(w_{1}^{(l)}, w_{2}^{(l)}, \ldots, w_{n}^{(l)}\right), l=1,2, \ldots, n$. It should be noted that the weight vector can be determined using analytic hierarchy process, Entropy (Shannon 1948; Sušinskas et al. 2011), LINMAP (Yoon, Hwang 1995; Mikhailov 2000, 2003; Xia et al. 2006; Li, Liu 2008), SWARA (Keršulienè et al. 2010), or any other methods. In the proposed approach, DMs can determine their weighting scheme linguistically.

\section{Aggregation}

To compute the decision-makers weight matrix $\lambda$, first, the individual decision matrices $X^{(l)}, l=1,2, \ldots, k$ are normalised. The normalised decision-making matrix $N^{(l)}=\left[\tilde{n}_{i j}^{(l)}\right]$ is constructed applying (Chen et al. 2006):

where

$$
\begin{aligned}
& \tilde{n}_{i j}^{(l)}=\left(\frac{x_{1 i j}^{(l)}}{x_{3 i j}^{(l) *}}, \frac{x_{2 i j}^{(l)}}{x_{3 i j}^{(l) *}}, \frac{x_{3 i j}^{(l)}}{x_{3 i j}^{(l) *}}\right), \\
& x_{3 i j}^{(l) *}=\max _{i}\left(x_{3 i j}^{(l)}\right), \text { for benefit type attributes, } \\
& \tilde{n}_{i j}^{(l)}=\left(\frac{x_{1 i j}^{(l)-}}{x_{3 i j}^{(l)}}, \frac{x_{1 i j}^{(l)-}}{x_{2 i j}^{(l)}}, \frac{x_{1 i j}^{(l)-}}{x_{1 i j}^{(l)}}\right), \text { for cost type attributes, }
\end{aligned}
$$

$$
x_{1 i j}^{(l)-}=\min _{i}\left(x_{1 i j}^{(l)}\right)
$$


Then, the weighted normalised decision matrix $V^{(l)}=\left[\tilde{v}_{i j}^{(l)}\right]=\left[\left(v_{1 i j}^{(l)}, v_{2 i j}^{(l)}, v_{3 i j}^{(l)}\right)\right]$ is specified by multiplying the weight vector $W^{(l)}$ in $N^{(l)}$,

$$
v_{i j}^{(l)}=w_{j} \tilde{n}_{i j}^{(l)} .
$$

Now, the vector $v_{j}=\left(\tilde{v}_{1 j}^{(1)}, \tilde{v}_{2 j}^{(1)}, \ldots, \tilde{v}_{m j}^{(1)}, \tilde{v}_{1 j}^{(2)}, \tilde{v}_{2 j}^{(2)}, \ldots, \tilde{v}_{m j}^{(2)}, \ldots, \tilde{v}_{1 j}^{(k)}, \tilde{v}_{2 j}^{(k)}, \ldots, \tilde{v}_{m j}^{(k)}\right)$, composing the weighted-normalised vectors of decision-makers over $j^{\text {th }}$ attribute. The most compromising solution $(B)$ for attribute $j$ is defined as follows:

Definition 1. Considering the vector $v_{j}$, the most compromising solution is an artificial point $B_{j}=\left(l_{j}^{+}, m_{j}^{+}, u_{j}^{+}\right)$, which has the least total square Euclidean distance from components of $v_{j}$, defined as follows:

$$
T D\left(v_{j}, B_{j}\right)=\sum_{l=1}^{k} \sum_{i=1}^{m} D^{2}\left(\tilde{v}_{i j}^{(1)}, B_{j}\right) .
$$

Similarly, the least compromising solution $(L)$ is defined.

Definition 2. Considering the vector $v_{j}$, the least compromising solution is an artificial point $L_{j}=\left(l_{j}^{-}, m_{j}^{-}, u_{j}^{-}\right)$, which has the least total square Euclidean distance from components of $v_{j}$, defined as follows:

$$
\operatorname{TD}\left(v_{j}, L_{j}\right)=\sum_{l=1}^{k} \sum_{i=1}^{m} D^{2}\left(\tilde{v}_{i j}^{(1)}, L_{j}\right) .
$$

A mathematical model can be developed to find $B_{j}$. This model is extended as follows:

$$
\begin{aligned}
& \min \sum_{l=1}^{k} \sum_{i=1}^{m} D^{2}\left(\tilde{v}_{i j}^{(1)}, B_{j}\right) ; \\
& \min _{1 \leq l \leq k} \min \left(v_{1 \leq i j}^{(l)}\right) \leq l_{j}^{+} \leq \max _{1 \leq l \leq k} \max \left(v_{1 \leq m}\left(v_{1 i j}^{(l)}\right) ;\right. \\
& \min _{1 \leq l \leq k} \min \left(v_{2 i j}^{(l)}\right) \leq m_{j}^{+} \leq \max _{1 \leq l \leq k} \max \left(v_{2 i j}^{(l)}\right) ; \\
& \min _{1 \leq l \leq k 1 \leq i \leq m} \min \left(v_{3 i j}^{(l)}\right) \leq u_{j}^{+} \leq \max _{1 \leq l \leq k} \max \left(v_{1 \leq i \leq m}^{(l)}\right) ; \\
& l_{j}^{+} \leq m_{j}^{+} \leq u_{j}^{+} .
\end{aligned}
$$

Absolutely, according to arithmetic average properties (Aladjev, Horitonov 2004), the average of decision-makers' opinions is the obvious solution of the model (16) and, therefore, $B_{j}$ is calculated as follows:

$$
\left(l_{j}^{+}, m_{j}^{+}, u_{j}^{+}\right)=\frac{1}{m l}\left(\sum_{l=1}^{k} \sum_{i=1}^{m} v_{1 i j}^{(l)}, \sum_{l=1}^{k} \sum_{i=1}^{m} v_{2 i j}^{(l)}, \sum_{l=1}^{k} \sum_{i=1}^{m} v_{3 i j}^{(l)}\right) .
$$

Similarly, the $L$ solution $\left(l_{j}^{-}, m_{j}^{-}, u_{j}^{-}\right)$is determined, replacing $\left(l_{j}^{+}, m_{j}^{+}, u_{j}^{+}\right)$in Eqs (16)(18) with $\left(l_{j}^{-}, m_{j}^{-}, u_{j}^{-}\right)$and maximising the corresponding model with the following objective function:

$$
\max \frac{1}{3}\left[\sum_{l=1}^{k} \sum_{i=1}^{m}\left(v_{1 i j}^{(l) 2}+v_{2 i j}^{(l) 2}+v_{3 i j}^{(l) 2}\right)-2 l_{j}^{-} \sum_{l=1}^{k} \sum_{i=1}^{m} v_{1 i j}^{(l)}-2 m_{j}^{-} \sum_{l=1}^{k} \sum_{i=1}^{m} v_{2 i j}^{(l)}-2 u_{j}^{-} \sum_{l=1}^{k} \sum_{i=1}^{m} v_{3 i j}^{(l)}+k m\left(l_{j}^{-2}+m_{j}^{-2}+u_{j}^{-2}\right)\right] .
$$


Replacing the above equation in Eq. (15), a quadratic programming model is obtained. Since the constraints of the problem include a set of linear constraints, which construct a convex set, the optimal solution of the problem can be easily determined using ordinal optimisation software, e.g. LINGO, LINDO, or AIMS. Solving this model, the optimal values of $\left(l_{j}^{+}, m_{j}^{+}, u_{j}^{+}\right)$are determined.

By applying the $B$ and $L$ models for each attribute, the positive ideal solution $(B)$ and negative ideal solution $(L)$ are determined: $B=\left(B_{1}, B_{2}, \ldots, B_{n}\right), L=\left(L_{1}, L_{2}, \ldots, L_{n}\right)$.

Now, consider the attribute $j$. The distance of each decision-maker in attribute $j$ from $B_{j}$ and $L_{j}$ is calculated:

$$
\begin{aligned}
& S_{l j}^{+}=\sqrt{\sum_{i=1}^{m} \frac{1}{3}\left[\left(v_{1 i j}^{(l)}-l_{j}^{+}\right)^{2}+\left(v_{2 i j}^{(l)}-m_{j}^{+}\right)^{2}+\left(v_{3 i j}^{(l)}-u_{j}^{+}\right)^{2}\right]}, l=1,2, \ldots, k ; j=1,2, \ldots, n ; \\
& S_{l j}^{-}=\sqrt{\sum_{i=1}^{m} \frac{1}{3}\left[\left(v_{1 i j}^{(l)}-l_{j}^{-}\right)^{2}+\left(v_{2 i j}^{(l)}-m_{j}^{-}\right)^{2}+\left(v_{3 i j}^{(l)}-u_{j}^{-}\right)^{2}\right]}, l=1,2, \ldots, k ; j=1,2, \ldots, n .
\end{aligned}
$$

The closeness coefficient of decision-maker $l$ in attribute $j$ to ideal solution is defined as

$$
w_{l j}=\frac{S_{l j}^{-}}{S_{l j}^{-}+S_{l j}^{+}}, l=1,2, \ldots, k ; j=1,2, \ldots, n .
$$

Finally, the weight of decision-maker $l$ in attribute $j$ is defined as:

$$
\lambda_{l j}=\frac{w_{l j}}{\sum_{l=1}^{k} w_{l j}}, l=1,2, \ldots, k ; j=1,2, \ldots, n .
$$

\section{Final Ranking}

Calculating the decision-maker weights of different attributes, the aggregated decision-making matrix $\tilde{X}$ is obtained,

$$
\tilde{X}=\left[\begin{array}{cccc}
\tilde{x}_{11} & \tilde{x}_{12} & \cdots & \tilde{x}_{1 n} \\
\tilde{x}_{21} & \tilde{x}_{22} & \cdots & \tilde{x}_{2 n} \\
\vdots & \vdots & \ddots & \vdots \\
\tilde{x}_{m 1} & \tilde{x}_{m 2} & \cdots & \tilde{x}_{m n}
\end{array}\right],
$$

where $\tilde{x}_{i j}=\sum_{l=1}^{k} \lambda_{l j} \tilde{v}_{i j}^{(k)}$. Now, the score of each alternative $A_{i}$ is computed as,

$$
\tilde{S}\left(A_{i}\right)=\sum_{j=1}^{n} \tilde{x}_{i j}, i=1,2, \ldots, m .
$$

The values of $\tilde{S}\left(A_{i}\right), i=1,2, \ldots, m$ are triangular fuzzy numbers. These values can be ordered using the centre of gravity (COG) method (Buckley, Eslami 2002). It should be kept in mind that for a triangular fuzzy number $\tilde{a}=\left(a_{1}, a_{2}, a_{3}\right)$, its COG is calculated as $\left(a_{1}+a_{2}+a_{3}\right) / 3$. The final ranking of alternatives is determined based on the descending ranking of their COG values.

The proposed algorithm for solving an FMAGDM problem could to be described as a step-wise procedure. It is presented in Figure 2. 


\section{Illustrative example}

In this section, the proposed algorithm (Fig. 2) is applied to assess the maintenance strategy in a corporation. Iran Foolad Kavir (IFK) is a steel and rolling company, which produces nine different types of reinforcing bars (rebar's) from 8 to $24 \mathrm{~mm}$ in diameter. Three different types of ingots are melted for the manufacturing process. At the first stage, the ingots are melted by smelter machines; then, the rolling machines produce specific sizes of the bars according to the production schedule. Depending on whether spare parts are purchased from a domestic or a foreign supplier, hiring domestic or foreign maintenance experts, and adopting a preventive or emergency maintenance approach, eight different strategies can be distinguished for the machinery system of IFK., as listed in Table 1.

The proposed algorithm is used to select the suitable maintenance strategy in IFK Co. Steps 1,2 , and 3 are completed by identifying the maintenance strategies and the evaluation

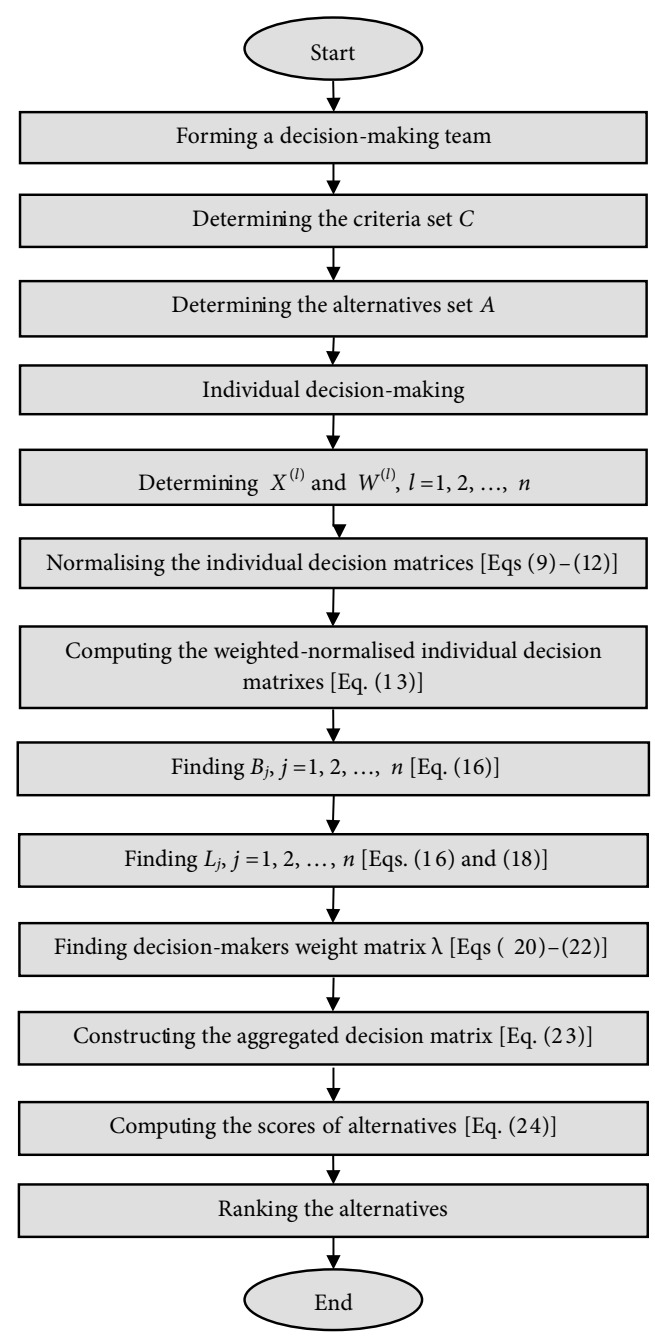

Fig. 2. Group multi-attribute decision-making process 
attributes, to construct the individual decision matrices. By replacing the equivalent triangular fuzzy numbers in Tables 3 and 4, the algorithm continues by step 4 - normalisation of individual matrices. It considers that accessibility, quality, and reliability are benefit-type attributes, while cost and time are cost-type attributes. Then, each of the individual normalised matrices is transformed into a weighted normalised matrix by Eq. (13). Table 6 presents the obtained weighted normalised matrices.

The aforementioned strategies can be compared based on five main attributes. Two of these attributes are quantitative, including cost and time of each decision, and three attributes are qualitative, including accessibility, quality and reliability of each strategy, which are implied from six experts from IFK, namely: the procurement manager, quality manager, operations manager, maintenance manager, financial manager, and human resources manager.

The predicted cost and time needed for each strategy are evaluated by the Maintenance Department and summarized in Table 2.

Table 3 indicates the proposed scale to show the importance of each strategy in each criterion, and the experts are asked to determine their opinions using the given scale. Also, each decision-maker expresses his/her opinion about attribute weights according to the scale given in Table 4.

Regarding the qualitative attributes, opinions of top-level managers were collected using linguistic terms. The results are shown in Table 5.

Table 1. Possible maintenance alternatives

\begin{tabular}{cccc}
\hline $\begin{array}{c}\text { Strategy } \\
\text { code }\end{array}$ & $\begin{array}{c}\text { Spare } \\
\text { parts }\end{array}$ & $\begin{array}{c}\text { Maintenance } \\
\text { men }\end{array}$ & Technology \\
\hline 1 & Domestic & Domestic & Emergency \\
\hline 2 & Domestic & Foreign & Emergency \\
\hline 3 & Domestic & Domestic & Preventive \\
\hline 4 & Domestic & Foreign & Preventive \\
\hline 5 & Foreign & Domestic & Emergency \\
\hline 6 & Foreign & Foreign & Emergency \\
\hline 7 & Foreign & Domestic & Preventive \\
\hline 8 & Foreign & Foreign & Preventive \\
\hline
\end{tabular}

Table 4. Linguistic terms for attribute weights

\begin{tabular}{cc}
\hline Linguistic term & TFN \\
\hline Very high & $(0.8,0.9,1.0)$ \\
\hline High & $(0.7,0.8,0.9)$ \\
\hline Moderately High & $(0.5,0.65,0.8)$ \\
\hline Moderate & $(0.4,0.5,0.6)$ \\
\hline Moderately Low & $(0.2,0.35,0.5)$ \\
\hline Low & $(0.1,0.2,0.3)$ \\
\hline Very low & $(0,0.1,0.2)$ \\
\hline
\end{tabular}

Table 2. Quantitative attributes: information on different maintenance strategies

\begin{tabular}{ccc}
\hline $\begin{array}{c}\text { Strategy } \\
\text { code }\end{array}$ & $\begin{array}{c}\text { Cost } \\
\text { (U.S.D.) }\end{array}$ & $\begin{array}{c}\text { Time } \\
\text { (weeks) }\end{array}$ \\
\hline 1 & 200,000 & 4 \\
\hline 2 & 250,000 & 6 \\
\hline 3 & 600,000 & 10 \\
\hline 4 & 275,000 & 9 \\
\hline 5 & 280,000 & 7 \\
\hline 6 & 250,000 & 6 \\
\hline 7 & 350,000 & 8 \\
\hline 8 & 450,000 & 6 \\
\hline
\end{tabular}

Table 3. Linguistic terms for strategy performance in attributes

\begin{tabular}{cc}
\hline Linguistic term & TFN \\
\hline Especially high & $(9,9,10)$ \\
\hline Very high & $(7,9,9)$ \\
\hline High & $(5,7,9)$ \\
\hline Ordinary & $(3,5,7)$ \\
\hline Low & $(1,3,5)$ \\
\hline Very low & $(0,1,3)$ \\
\hline Especially low & $(0,1,1)$ \\
\hline
\end{tabular}


Table 5. Individual decision matrices of experts

\begin{tabular}{|c|c|c|c|c|c|c|}
\hline Expert & Strategy & Accessibility & Quality & Reliability & Cost & Time \\
\hline & & $\tilde{x}_{1}$ & $\tilde{x}_{2}$ & $\tilde{x}_{3}$ & $\tilde{x}_{4}$ & $\tilde{x}_{5}$ \\
\hline \multirow{8}{*}{1} & 1 & $\mathrm{VVH}$ & $\mathrm{O}$ & $\mathrm{L}$ & 200,000 & 4 \\
\hline & 2 & $\mathrm{H}$ & $\mathrm{H}$ & $\mathrm{H}$ & 250,000 & 6 \\
\hline & 3 & $\mathrm{H}$ & $\mathrm{L}$ & $\mathrm{VL}$ & 600,000 & 10 \\
\hline & 4 & $\mathrm{H}$ & $\mathrm{H}$ & $\mathrm{L}$ & 275,000 & 9 \\
\hline & 5 & $\mathrm{H}$ & $\mathrm{VL}$ & $\mathrm{VL}$ & 280,000 & 7 \\
\hline & 6 & $\mathrm{H}$ & $\mathrm{H}$ & $\mathrm{H}$ & 250,000 & 6 \\
\hline & 7 & $\mathrm{VVH}$ & $\mathrm{VVH}$ & $\mathrm{VVH}$ & 350,000 & 8 \\
\hline & 8 & $\mathrm{~L}$ & VVH & VVH & 450,000 & 6 \\
\hline Attribute weights & & M & $\mathrm{H}$ & $\mathrm{H}$ & $\mathrm{M}$ & $\mathrm{MH}$ \\
\hline \multirow{8}{*}{2} & 1 & $\mathrm{VH}$ & $\mathrm{H}$ & $\mathrm{VL}$ & 200,000 & 4 \\
\hline & 2 & $\mathrm{VH}$ & $\mathrm{H}$ & $\mathrm{H}$ & 250,000 & 6 \\
\hline & 3 & $\mathrm{H}$ & VL & $\mathrm{VL}$ & 600,000 & 10 \\
\hline & 4 & $\mathrm{H}$ & $\mathrm{L}$ & $\mathrm{L}$ & 275,000 & 9 \\
\hline & 5 & $\mathrm{~L}$ & $\mathrm{~L}$ & $\mathrm{~L}$ & 280,000 & 7 \\
\hline & 6 & $\mathrm{H}$ & $\mathrm{H}$ & $\mathrm{H}$ & 250,000 & 6 \\
\hline & 7 & $\mathrm{H}$ & $\mathrm{H}$ & $\mathrm{H}$ & 350,000 & 8 \\
\hline & 8 & $\mathrm{O}$ & $\mathrm{H}$ & $\mathrm{H}$ & 450,000 & 6 \\
\hline Attribute weights & & $\mathrm{MH}$ & $\mathrm{H}$ & $\mathrm{H}$ & $\mathrm{MH}$ & $\mathrm{H}$ \\
\hline \multirow{8}{*}{3} & 1 & $\mathrm{VH}$ & $\mathrm{H}$ & $\mathrm{VL}$ & 200,000 & 4 \\
\hline & 2 & $\mathrm{VH}$ & $\mathrm{H}$ & $\mathrm{L}$ & 250,000 & 6 \\
\hline & 3 & $\mathrm{~L}$ & $\mathrm{~L}$ & $\mathrm{~L}$ & 600,000 & 10 \\
\hline & 4 & $\mathrm{~L}$ & $\mathrm{~L}$ & $\mathrm{~L}$ & 275,000 & 9 \\
\hline & 5 & $\mathrm{H}$ & $\mathrm{VL}$ & $\mathrm{VL}$ & 280,000 & 7 \\
\hline & 6 & $\mathrm{H}$ & $\mathrm{VH}$ & $\mathrm{H}$ & 250,000 & 6 \\
\hline & 7 & $\mathrm{VH}$ & $\mathrm{VH}$ & $\mathrm{VVH}$ & 350,000 & 8 \\
\hline & 8 & 0 & $\mathrm{H}$ & $\mathrm{H}$ & 450,000 & 6 \\
\hline Attribute weights & & ML & $\mathrm{H}$ & $\mathrm{H}$ & $\mathrm{VH}$ & $\mathrm{MH}$ \\
\hline \multirow{8}{*}{4} & 1 & $\mathrm{VH}$ & $\mathrm{H}$ & $\mathrm{VL}$ & 200,000 & 4 \\
\hline & 2 & $\mathrm{H}$ & $\mathrm{VH}$ & $\mathrm{O}$ & 250,000 & 6 \\
\hline & 3 & $\mathrm{H}$ & $\mathrm{L}$ & $\mathrm{L}$ & 600,000 & 10 \\
\hline & 4 & $\mathrm{~L}$ & $\mathrm{~L}$ & $\mathrm{~L}$ & 275,000 & 9 \\
\hline & 5 & $\mathrm{VH}$ & $\mathrm{H}$ & $\mathrm{L}$ & 280,000 & 7 \\
\hline & 6 & $\mathrm{VH}$ & $\mathrm{VH}$ & $\mathrm{VH}$ & 250,000 & 6 \\
\hline & 7 & $\mathrm{~L}$ & $\mathrm{VH}$ & $\mathrm{VH}$ & 350,000 & 8 \\
\hline & 8 & $\mathrm{~L}$ & $\mathrm{VH}$ & $\mathrm{VH}$ & 450,000 & 6 \\
\hline Attribute weights & & $\mathrm{M}$ & $\mathrm{H}$ & $\mathrm{H}$ & $\mathrm{M}$ & $\mathrm{MH}$ \\
\hline
\end{tabular}


End of Table 5

\begin{tabular}{|c|c|c|c|c|c|c|}
\hline Expert & Strategy & Accessibility & Quality & Reliability & Cost & Time \\
\hline & & $\tilde{x}_{1}$ & $\tilde{x}_{2}$ & $\tilde{x}_{3}$ & $\tilde{x}_{4}$ & $\tilde{x}_{5}$ \\
\hline \multirow{8}{*}{5} & 1 & $\mathrm{H}$ & $\mathrm{VL}$ & VVL & 200,000 & 4 \\
\hline & 2 & $\mathrm{~L}$ & $\mathrm{~L}$ & $\mathrm{~L}$ & 250,000 & 6 \\
\hline & 3 & $\mathrm{VL}$ & VL & VVL & 600,000 & 10 \\
\hline & 4 & $\mathrm{VL}$ & $\mathrm{L}$ & $\mathrm{L}$ & 275,000 & 9 \\
\hline & 5 & $\mathrm{~L}$ & $\mathrm{~L}$ & $\mathrm{~L}$ & 280,000 & 7 \\
\hline & 6 & $\mathrm{VH}$ & VH & $\mathrm{VH}$ & 250,000 & 6 \\
\hline & 7 & $\mathrm{VVH}$ & VVH & VH & 350,000 & 8 \\
\hline & 8 & $\mathrm{H}$ & VVH & VVH & 450,000 & 6 \\
\hline Attribute weights & & ML & $\mathrm{H}$ & $\mathrm{H}$ & $\mathrm{H}$ & $\mathrm{M}$ \\
\hline \multirow{8}{*}{6} & 1 & $\mathrm{VVH}$ & $\mathrm{VH}$ & $\mathrm{H}$ & 200,000 & 4 \\
\hline & 2 & $\mathrm{VH}$ & $\mathrm{VH}$ & $\mathrm{VH}$ & 250,000 & 6 \\
\hline & 3 & $\mathrm{~L}$ & $\mathrm{~L}$ & $\mathrm{~L}$ & 600,000 & 10 \\
\hline & 4 & $\mathrm{VL}$ & $\mathrm{VL}$ & $\mathrm{VL}$ & 275,000 & 9 \\
\hline & 5 & $\mathrm{VH}$ & $\mathrm{H}$ & $\mathrm{L}$ & 280,000 & 7 \\
\hline & 6 & $\mathrm{~L}$ & $\mathrm{~L}$ & $\mathrm{~L}$ & 250,000 & 6 \\
\hline & 7 & $\mathrm{VH}$ & $\mathrm{VH}$ & $\mathrm{VH}$ & 350,000 & 8 \\
\hline & 8 & $\mathrm{H}$ & VVH & $\mathrm{VVH}$ & 450,000 & 6 \\
\hline Attribute weights & & $\mathrm{ML}$ & $\mathrm{H}$ & $\mathrm{H}$ & $\mathrm{M}$ & $\mathrm{MH}$ \\
\hline
\end{tabular}

In step 6 , the $B$ s are determined by calculating the average values of triangular fuzzy numbers in weighted normalised matrices for each of the attributes. Thus, the $P$ vector is computed as demonstrated below:

$B:[(0.156,0.305,0.481) ;(0.303,0.485,0.685) ;(0.238,0.404,0.597) ;(0.359,0.432,0.505)$; $(0.317,0.399,0.481)]$.

Table 6. Individual weighted normalised decision matrices

\begin{tabular}{|c|c|c|c|c|c|c|}
\hline 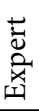 & 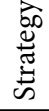 & $\tilde{\bar{x}}_{1}$ & $\tilde{\bar{x}}_{2}$ & $\tilde{\bar{x}}_{3}$ & $\tilde{\bar{x}}_{4}$ & $\tilde{\bar{x}}_{5}$ \\
\hline \multirow[t]{8}{*}{1} & 1 & $(0.36,0.45,0.6)$ & $(0.21,0.4,0.63)$ & $(0.07,0.24,0.45)$ & $(0.4,0.5,06)$ & $(0.5,0.65,0.8)$ \\
\hline & 2 & $(0.2,0.35,0.54)$ & $(0.35,0.56,0.81)$ & $(0.35,0.56,0.81)$ & $(0.32,0.4,0.48)$ & $(0.333,0.433,0.533)$ \\
\hline & 3 & $(0.2,0.35,0.54)$ & $(0.07,0.24,0.45)$ & $(0,0.08,0.27)$ & $(0.133,0.167,0.2)$ & $(0.2,0.26,0.32)$ \\
\hline & 4 & $(0.2,0.35,0.54)$ & $(0.35,0.56,0.81)$ & $(0.07,0.24,0.45)$ & $(0.291,0.364,0.436)$ & $(0.222,0.289,0.356)$ \\
\hline & 5 & $(0.2,0.35,0.54)$ & $(0,0.08,0.27)$ & $(0,0.08,0.27)$ & $(0.286,0.357,0.429)$ & $(0.286,0.371,0.457)$ \\
\hline & 6 & $(0.2,0.35,0.54)$ & $(0.35,0.56,0.81)$ & $(0.35,0.56,0.81)$ & $(0.32,0.4,0.48)$ & $(0.333,0.433,0.533)$ \\
\hline & 7 & $(0.36,0.45,0.6)$ & $(0.63,0.72,0.9)$ & $(0.63,0.72,0.9)$ & $(0.229,0.286,0.343)$ & $(0.25,0.325,0.4)$ \\
\hline & 8 & $(0.04,0.15,0.3)$ & $(0.63,0.72,0.9)$ & $(0.63,0.72,0.9)$ & $(0.178,0.222,0.267)$ & $(0.333,0.433,0.533)$ \\
\hline
\end{tabular}


End of Table 6

\begin{tabular}{|c|c|c|c|c|c|c|}
\hline 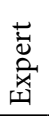 & 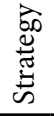 & $\tilde{\bar{x}}_{1}$ & $\tilde{\bar{x}}_{2}$ & $\tilde{\bar{x}}_{3}$ & $\tilde{\bar{x}}_{4}$ & $\tilde{\bar{x}}_{5}$ \\
\hline \multirow{8}{*}{2} & 1 & $(0.389,0.65,0.8)$ & $(0.389,0.622,0.9)$ & $(0,0.089,0.3)$ & $(0.5,0.65,0.8)$ & $(0.7, .8,0.9)$ \\
\hline & 2 & $(0.389,0.65,0.8)$ & $(0.389,0.622,0.9)$ & $(0.389,0.622,0.9)$ & $(0.4,0.52,0.64)$ & $(0.467,0.533,0.6)$ \\
\hline & 3 & $(0.278,0.506,0.8)$ & $(0,0.089,0.3)$ & $(0,0.089,0.3)$ & $(0.167,0.217,0.267)$ & $(0.28,0.32,0.36)$ \\
\hline & 4 & $(0.278,0.506,0.8)$ & $(0.078,0.267,0.5)$ & $(0.078,0.267,0.5)$ & $(0.364,0.473,0.582)$ & $(0.311,0.356,0.4)$ \\
\hline & 5 & $(0.056,0.217,0.444)$ & $(0.078,0.267,0.5)$ & $(0.078,0.267,0.5)$ & $(0.357,0.464,0.571)$ & $(0.4,0.457,0.514)$ \\
\hline & 6 & $(0.278, .506,0.8)$ & $(0.389,0.622,0.9)$ & $(0.389,0.622,0.9)$ & $(0.4,0.52,0.64)$ & $(0.467,0.533, .6)$ \\
\hline & 7 & $(0.278, .506,0.8)$ & $(0.389,0.622,0.9)$ & $(0.389,0.622,0.9)$ & $(0.286,0.371,0.457)$ & $(0.35,0.4,0.45)$ \\
\hline & 8 & $(0.167,0.361,0.622)$ & $(0.389,0.622,0.9)$ & $(0.389,0.622,0.9)$ & $(0.222,0.289,0.356)$ & $(0.467,0.533,0.6)$ \\
\hline \multirow{8}{*}{3} & 1 & $(0.156,0.35,0.5)$ & $(0.35,0.56,0.81)$ & $(0,0.08,0.27)$ & $(0.8,0.9,1)$ & $(0.5,0.65,0.8)$ \\
\hline & 2 & $(0.156,0.35,0.5)$ & $(0.35,0.56,0.81)$ & $(0.07,0.24,0.45)$ & $(0.64,0.72,0.8)$ & $(0.333,0.433,0.533)$ \\
\hline & 3 & $(0.022,0.117,0.278)$ & $(0.07,0.24,0.45)$ & $(0.07,0.24,0.45)$ & $(0.267,0.3,0.333)$ & $(0.2,0.26,0.32)$ \\
\hline & 4 & $(0.022,0.117,0.278)$ & $(0.07,0.24,0.45)$ & $(0.07,0.24,0.45)$ & $(0.582,0.655,0.727)$ & $(0.222,0.289,0.356)$ \\
\hline & 5 & $(0.111,0.272,0.5)$ & $(0,0.08,0.27)$ & $(0,0.08,0.27)$ & $(0.571,0.643,0.714)$ & $(0.286,0.371,0.457)$ \\
\hline & 6 & $(0.111,0.272,0.5)$ & $(0.49,0.72,0.81)$ & $(0.35,0.56,0.81)$ & $(0.64,0.72,0.8)$ & $(0.333,0.433,0.533)$ \\
\hline & 7 & $(0.156,0.35,0.5)$ & $(0.49,0.72,0.9)$ & $(0.63,0.72,0.9)$ & $(0.457,0.514,0.571)$ & $(0.25,0.325,0.4)$ \\
\hline & 8 & $(0.067,0.194,0.389)$ & $(0.35,0.56,0.81)$ & $(0.35,0.56,0.81)$ & $(0.356,0.4,0.444)$ & $(0.333,0.433,0.533)$ \\
\hline \multirow{8}{*}{4} & 1 & $(0.311,0.5,0.6)$ & $(0.389,0.622,0.9)$ & $(0,0.089,0.3)$ & $(0.4,0.5,0.6)$ & $(0.5,0.65,0.8)$ \\
\hline & 2 & $(0.222,0.389,0.6)$ & $(0.544,0.8,0.9)$ & $(0.233,0.444,0.7)$ & $(0.32,0.4,0.48)$ & $(0.333,0.433,0.533)$ \\
\hline & 3 & $(0.222,0.389,0.6)$ & $(0.078,0.267,0.5)$ & $(0.078,0.267,0.5)$ & $(0.133,0.167,0.2)$ & $(0.2,0.26,0.32)$ \\
\hline & 4 & $(0.044,0.167,0.333)$ & $(0.078,0.267,0.5)$ & $(0.078,0.267,0.5)$ & $(0.291,0.364,0.436)$ & $(0.222,0.289,0.356)$ \\
\hline & 5 & $(0.311,0.5,0.6)$ & $(0.389,0.622,0.9)$ & $(0.078,0.267,0.5)$ & $(0.286,0.357,0.429)$ & $(0.286,0.371,0.457)$ \\
\hline & 6 & $(0.311,0.5,0.6)$ & $(0.544,0.8,0.9)$ & $(0.544,0.8,0.9)$ & $(0.32,0.4,0.48)$ & $(0.333,0.433,0.533)$ \\
\hline & 7 & $(0.044,0.167,0.333)$ & $(0.544,0.8,0.9)$ & $(0.544,0.8,0.9)$ & $(0.229,0.286,0.343)$ & $(0.25,0.325,0.4)$ \\
\hline & 8 & $(0.044,0.167,0.333)$ & $(0.544,0.8,0.9)$ & $(0.544,0.8,0.9)$ & $(0.178,0.222,0.267)$ & $(0.333,0.433,0.533)$ \\
\hline \multirow{8}{*}{5} & 1 & $(0.1,0.245,0.45)$ & $(0,0.08,0.27)$ & $(0,0.08,0.09)$ & $(0.7,0.8,0.9)$ & $(0.4,0.5,0.6)$ \\
\hline & 2 & $(0.02,0.105,0.25)$ & $(0.07,0.24,0.45)$ & $(0.07,0.24,0.45)$ & $(0.56,0.64,0.72)$ & $(0.267,0.333,0.4)$ \\
\hline & 3 & $(0,0.035,0.15)$ & $(0,0.08,0.27)$ & $(0,0.08,0.09)$ & $(0.233,0.267,0.3)$ & $(0.160,0.2,0.24)$ \\
\hline & 4 & $(0,0.035,0.15)$ & $(0.07,0.24,0.45)$ & $(0.07,0.24,0.45)$ & $(0.509,0.582,0.655)$ & $(0.178,0.222,0.267)$ \\
\hline & 5 & $(0.02,0.105,0.25)$ & $(0.07,0.24,0.45)$ & $(0.07,0.24,0.45)$ & $(0.5,0.571,0.643)$ & $(0.229,0.286,0.343)$ \\
\hline & 6 & $(0.14,0.315,0.45)$ & $(0.49,0.72,0.81)$ & $(0.49,0.72,0.81)$ & $(0.56,0.64,0.72)$ & $(0.267,0.333,0.4)$ \\
\hline & 7 & $(0.18,0.315,0.5)$ & $(0.63,0.72,0.9)$ & $(0.49,0.72,0.81)$ & $(0.4,0.457,0.514)$ & $(0.2,0.25,0.3)$ \\
\hline & 8 & $(0.1,0.245,0.45)$ & $(0.63,0.72,0.9)$ & $(0.63,0.72,0.9)$ & $(0.311,0.356,0.4)$ & $(0.267,0.333,0.4)$ \\
\hline \multirow{8}{*}{6} & 1 & $(0.18,0.315,0.5)$ & $(0.49,0.72,0.81)$ & $(0.35,0.56,0.81)$ & $(0.4,0.5,0.6)$ & $(0.5,0.65,0.8)$ \\
\hline & 2 & $(0.14,0.315,0.45)$ & $(0.49,0.72,0.81)$ & $(0.49,0.72,0.81)$ & $(0.32,0.4,0.48)$ & $(0.333,0.433,0.533)$ \\
\hline & 3 & $(0.02,0.105,0.25)$ & $(0.07,0.24,0.45)$ & $(0.07,0.24,0.45)$ & $(0.133,0.167,0.2)$ & $(0.2,0.26,0.32)$ \\
\hline & 4 & $(0,0.035,0.15)$ & $(0,0.08,0.27)$ & $(0,0.08,0.27)$ & $(0.291,0.364,0.436)$ & $(0.222,0.289,0.356)$ \\
\hline & 5 & $(0.14,0.315,0.45)$ & $(0.35,0.56,0.81)$ & $(0.07,0.24,0.45)$ & $(0.286,0.357,0.429)$ & $(0.286,0.371,0.457)$ \\
\hline & 6 & $(0.02,0.105,0.25)$ & $(0.07,0.24,0.45)$ & $(0.07,0.24,0.45)$ & $(0.32,0.4,0.48)$ & $(0.333,0.433,0.533)$ \\
\hline & 7 & $(0.14,0.315,0.45)$ & $(0.49,0.72,0.81)$ & $(0.49,0.72,0.81)$ & $(0.229,0.286,0.343)$ & $(0.25,0.325,0.4)$ \\
\hline & 8 & $(0.1,0.245,0.45)$ & $(0.63,0.72,0.9)$ & $(0.63,0.72,0.9)$ & $(0.178,0.222,0.267)$ & $(0.333,0.433,0.533)$ \\
\hline
\end{tabular}


To determine the Ls, the mathematical problem in Eq. (16) is solved by replacing Eq. (18) in its objective function for each attribute.

$L:[(0.389,0.65,0.8) ;(0,0.08,0.27) ;(0,0.08,0.09) ;(0.8,0.9,1) ;(0.7,0.8,0.9)]$.

The weight matrix of decision-makers is now computed by using Eqs (19) to (22) based on the above $P$ and $R$ vectors. This matrix is formed as follows:

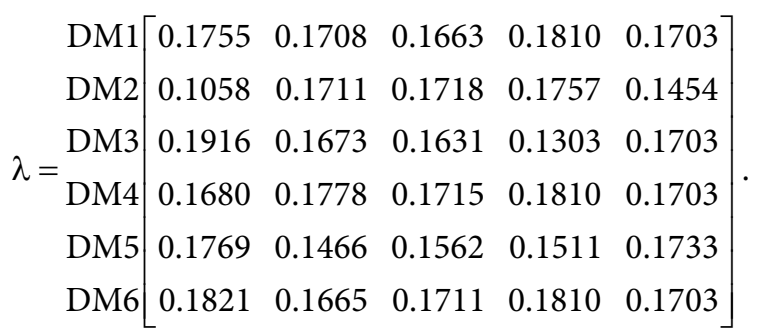

Applying Eq. (23) yields the aggregated decision matrix as listed in Table 7.

Table 7. Aggregated decision matrix

\begin{tabular}{|c|c|c|c|c|c|}
\hline 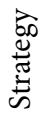 & $\tilde{x}_{1}$ & $\tilde{x}_{2}$ & $\tilde{x}_{3}$ & $\tilde{R}^{2}$ & $\tilde{x}_{5}$ \\
\hline 1 & $(0.974,1.642,2.290)$ & $(1.229,2.013,2.884)$ & $(0.277,0.743,1.450)$ & $(2.289,2.773,3.256)$ & $(2.349,2.964,3.580)$ \\
\hline 2 & $(0.709,1.391,2.064)$ & $(1.472,2.338,3.109)$ & $(1.050,1.843,2.678)$ & $(1.831,2.218,2.605)$ & $(1.566,1.976,2.387)$ \\
\hline 3 & $(0.451,0.937,1.667)$ & $(0.194,0.770,1.64)$ & $(0.142,0.647,1.342)$ & $(0.763,0.924,1.085)$ & $(0.940,1.186,1.432)$ \\
\hline 4 & $(0.313,0.731,1.408)$ & $(0.429,1.093,1.967)$ & $(0.235,0.859,1.689)$ & $(1.665,2.017,2.368)$ & $(1.044,1.318,1.591)$ \\
\hline 5 & $(0.590,1.218,1.910)$ & $(0.595,1.229,2.119)$ & $(0.192,0.761,1.579)$ & $(1.635,1.981,2.326)$ & $(1.342,1.694,2.046)$ \\
\hline 6 & $(0.684,1.340,2.060)$ & $(1.532,2.406,3.080)$ & $(1.409,2.254,3.017)$ & $(1.831,2.218,2.605)$ & $(1.566,1.976,2.387)$ \\
\hline 7 & $(0.769,1.400,2.105)$ & $(2.077,2.828,3.489)$ & $(2.045,2.776,3.370)$ & $(1.308,1.584,1.861)$ & $(1.175,1.482,1.790)$ \\
\hline 8 & $(0.332,0.895,1.688)$ & $(2.076,2.723,3.488)$ & $(2.045,2.675,3.428)$ & $(1.017,1.232,1.447)$ & $(1.566,1.976,2.387)$ \\
\hline
\end{tabular}

Eq. (24), calculates the score of different strategies:

$$
\begin{array}{ll}
\tilde{S}\left(A_{1}\right)=(7.117,10.135,13.460) & \tilde{S}\left(A_{2}\right)=(6.629,9.767,12.842) \\
\tilde{S}\left(A_{3}\right)=(2.490,4.464,7.130) & \tilde{S}\left(A_{4}\right)=(3.686,6.017,9.023) \\
\tilde{S}\left(A_{5}\right)=(4.355,6.882,9.980) & \tilde{S}\left(A_{6}\right)=(7.022,10.193,13.149) \\
\tilde{S}\left(A_{7}\right)=(7.373,10.071,12.615) & \tilde{S}\left(A_{8}\right)=(7.037,9.501,12.437)
\end{array}
$$

Calculating COG for the alternative scores, the selected strategy is chosen, i.e. to buy spare parts from domestic suppliers by hiring domestic maintenance experts for emergencies. According to Table 1, the next two strategies are the $6^{\text {th }}$ and the $7^{\text {th }}$. 


\section{Conclusions}

In real world, decision-making problems always consist of evaluation of a set of alternatives based on a set of attributes. The complexity of such problems makes it unsolvable by a single decision-maker in a crisp mode. In fact, most of the real world decisions are made by incorporating a group of experts who explain their judgments on the performance of alternatives with uncertain information. A considerable issue is whether to consider an opinion of the decision-making group member as equally important or not. An important consideration is that different people have different specialties; therefore, their opinions become issues of unequal importance in different attributes. Researchers are concerned with this problem in the context of calculating weights of decision-makers. This paper presents a method for calculation of weights of decision-makers participating in a group decision-making. The main idea behind the paper was to assign weights to decision-makers according to the consistency of their opinion with the most compromising solution in each attribute. Therefore, a quadratic programming model was developed to find the most and least compromising solutions in each attribute. Then, the closeness coefficient of each decision-maker was considered to calculate his/her weight in different attributes. These weights were then used to aggregate individual preferences and to make the final decision. The proposed algorithm has some advantages in comparison to previous methods: first, this model can be used in a fuzzy environment. Second, different weights are computed for each decision-maker in each decision-making attribute, which has more coincidence with the fact that different people have different competences in various attributes. Third, like most of the previous studies, the average of decision-maker opinions is considered as the positive ideal solution, which makes the total square of distances as little as possible. Also, a quadratic programming model is solved to find the negative ideal solution. Then, these points play the role of reference points to determine the weights of decision-makers. Application of the proposed method is examined in a problem of maintenance strategy selection, where a decision-making team was formed from experts. It is expected that different expert weights will provide a larger degree of acceptability of the results.

\section{References}

Arrow, K. J. 1950. A difficulty in the concept of social welfare, Journal of Political Economy 58(4): 328-346. http://dx.doi.org/10.1086/256963

Aladjev, V. Z.; Haritonov, V. N. 2004. General theory of statistics. Palo Alto: Fultus Publishing.

Bellman, R. E.; Zadeh, L. A. 1970. Decision-making in a fuzzy environment, Management Sciences 17(4): B-141-B-164. http://dx.doi.org/10.1287/mnsc.17.4.B141

Buckley, J. J.; Eslami, E. 2002. An introduction to fuzzy logic and fuzzy sets. New York: Phisica-Verlag. http://dx.doi.org/10.1007/978-3-7908-1799-7

Chaudhuri, A.; Krishna Mohanty, B.; Nareshsingh, K. 2013. Supply chain risk assessment during new product development: a group decision making approach using numeric and linguistic data, International Journal of Production Research 51(10): 2790-2804.

http://dx.doi.org/10.1080/00207543.2012.654922

Chen, C. T. 2000. Extensions of the TOPSIS for group decision-making under fuzzy environment, Fuzzy Sets and Systems 114(1): 1-9. http://dx.doi.org/10.1016/S0165-0114(97)00377-1 
Chen, C.-T.; Lin, C.-T.; Huang, S.-F. 2006. A fuzzy approach for supplier evaluation and selection in supply chain management, International Journal of Production Economics 102: 289-301. http://dx.doi.org/10.1016/j.ijpe.2005.03.009

Chen, X.; Fan, Z. 2007. Study on assessment level of experts based on difference preference information, Systems-Engineering Theory and Practice 27(2): 27-35. http://dx.doi.org/10.1016/S1874-8651(08)60009-5

Condorcet, M. de. 1785. Essai sur l'application de lanalyse a la probabilite des decisions rendues a la pluralite des voix. Paris.

Devi, K.; Yadav, S. P. 2013. A multicriteria intuitionistic fuzzy group decision making for plant location selection with ELECTRE method, International Journal of Advanced Manufacturing Technology 66(9-12): 1219-1229. http://dx.doi.org/10.1007/s00170-012-4400-0

Dong, Q.; Saaty, T. L. 2014. An Analytic Hierarchy Process model of group decision making, Journal of Systems Science and Systems Engineering 23(3): 362-374.

http://dx.doi.org/10.1007/s11518-014-5247-8

Hwang, C.-L.; Lin, M.-J. 1986. Group decision making under multiple criteria: methods and applications. Berlin Heidelberg: Springer.

Hwang, C.-L.; Yoon, K. 1981. Multiple attribute decision making methods and applications. Berlin: Springer-Verlag. http://dx.doi.org/10.1007/978-3-642-48318-9

Ishizaka, A.; Nemery, P. 2013. Multicriteria decision aid: methods and software. Chichester: Wiley.

Jabeur, K.; Martel, J. 2002. Quantification de l'importance relative des membresd' ungroupeenvue de determiner un preorder collectif, Information Systems and Operational Research 40(3): 181-198.

Jabeur, K.; Martel, J.; Khelif, S. 2004. A distance-based collective preorder integrating the relative importance of the group's members, Group Decision and Negotiation 13(4): 327-349. http://dx.doi.org/10.1023/B:GRUP.0000042894.00775.75

Kahraman, C.; Ruan, D.; Dogan, I. 2007. Fuzzy group decision-making for facility location selection, Information Science 157: 135-153. http://dx.doi.org/10.1016/S0020-0255(03)00183-X

Kaufmann, A.; Gupta, M. M. 1991. Introduction to fuzzy arithmetic: theory and applications. New York: Van Nostrand Reinhold.

Keršulienė, V.; Turskis, Z. 2014. A hybrid linguistic fuzzy multiple criteria group selection of a chief accounting officer, Journal of Business Economics and Management 15(2): 232-252. http://dx.doi.org/10.3846/16111699.2014.903201

Keršuliene, V.; Zavadskas, E. K.; Turskis, Z. 2010. Selection of rational dispute resolution method by applying new step-wise weight assessment ratio analysis (SWARA), Journal of Business Economics and Management 11(2): 243-258. http://dx.doi.org/10.3846/jbem.2010.12

Kreinovich, V. 2014. Interval computations and interval-related statistical techniques: estimating uncertainty of the results of data processing and indirect measurements [online], [cited 29 May 2015]. Available from Internet: http://www.google.lt/url?sa=t\&rct=j\&q=\&esrc=s\&source=web\&cd=1\&ve $\mathrm{d}=0 \mathrm{CCMQFjAA} \& u r l=$ http\%3A\%2F\%2Fdigitalcommons.utep.edu\%2Fcgi\%2Fviewcontent.cgi\%3F article\%3D1884\%26context\%3Dcs_techrep\&ei=4nZoVZPcDILwUpa7gpgJ\&usg=AFQjCNFytGK kj-rUgwov_0NrhItlh2Iu6Q

Leung, Y. 1988. Spatial analysis and planning under imprecision. Amsterdam: North Holland.

Li, X.; Chen, X. 2014. Extension of the TOPSIS method based on prospect theory and trapezoidal intuitionistic fuzzy numbers for group decision making, Journal of Systems Science and Systems Engineering 23(2): 231-247. http://dx.doi.org/10.1007/s11518-014-5244-y

Li, P.; Liu, B. 2008. Entropy of credibility distribution for fuzzy variables, IEEE Transactions on Fuzzy Systems 16(1): 123-129. http://dx.doi.org/10.1109/TFUZZ.2007.894975

Mikhailov, L. 2000. A fuzzy programming method for deriving priorities in the analytic hierarchy process, Journal of the Operational Research Society 51(3): 341-349.

http://dx.doi.org/10.1057/palgrave.jors.2600899 
Mikhailov, L. 2003. Deriving priorities from fuzzy pairwise comparison judgments, Fuzzy Sets and Systems 134(3): 365-385. http://dx.doi.org/10.1016/S0165-0114(02)00383-4

Ramanathan, R.; Ganesh, L. 1994. Group preference aggregation methods employed in AHP: an evaluation and an intrinsic process for deriving members' weightages, European Journal of Operational Research 79(2): 249-265. http://dx.doi.org/10.1016/0377-2217(94)90356-5

Saaty, T. L. 1980. The analytic hierarchy process: planning, priority setting, resource allocation. McGrawHill. ISBN 0-07-054371-2.

Saaty, T. L.; Peniwati, K. 2008. Group decision making: drawing out and reconciling differences. Pittsburgh, Pennsylvania: RWS Publications. ISBN 978-1-888603-08-8.

Shannon, C. E. 1948. The mathematical theory of communication, Bell System Technical Journal 27(3): 379-423. http://dx.doi.org/10.1002/j.1538-7305.1948.tb01338.x

Sušinskas, S.; Zavadskas, E. K.; Turskis, Z. 2011. Multiple criteria assessment of pile-columns alternatives, The Baltic Journal of Road and Bridge Engineering 6(3): 77-83. http://dx.doi.org/10.3846/bjrbe.2011.19

Venkata, R. R. 2013. Decision making in manufacturing environment using graph theory and fuzzy multiple attribute decision making methods. Springer Series in Advanced Manufacturing, Vol. 2. London, UK: Springer-Verlag.

Visco, I. 2014. Lawrence R. Klein: macroeconomics, econometrics and economic policy, Journal of Policy Modeling 36: 605-628. http://dx.doi.org/10.1016/j.jpolmod.2014.03.003

Xia, H. C.; Li, D. F.; Zhou, J. Y.; Wang, J. M. 2006.Fuzzy LINMAP methods for multi attribute decision making under fuzzy environments, Journal of Computer and System Sciences 72(4): 741-759. http://dx.doi.org/10.1016/j.jcss.2005.11.001

$\mathrm{Xu}, \mathrm{Z} .2015$. Uncertain multi-attribute decision making: methods and applications. Springer. http://dx.doi.org/10.1007/978-3-662-45640-8

Xu, Y.; Patnayakuni, R.; Wang, H. 2013. Logarithmic least squares method to priority for group decision making with incomplete fuzzy preference relations, Applied Mathematical Modelling 37(4): 2139-2152. http://dx.doi.org/10.1016/j.apm.2012.05.010

Yovits, M. C. 1984. Advances in computers, vol. 23. Florida: Academic Press Inc.

Yoon, K. P.; Hwang, C.-L. 1995. Multiple attribute decision making: an introduction. Thousand Oaks, USA: Sage Publications.

Yue, Z. 2011a. A method for group decision-making based on determining weights of decision makers using TOPSIS, Applied Mathematical Modelling 35(4): 1926-1936. http://dx.doi.org/10.1016/j.apm.2010.11.001

Yue, Z. 2011b. An extended TOPSIS for determining weights of decision makers with interval numbers, Knowledge-Based Systems 24(1): 146-153. http://dx.doi.org/10.1016/j.knosys.2010.07.014

Yue, Z. 2011c. Deriving decision maker's weights based on distance measure for interval-valued intuitionistic fuzzy group decision making, Expert Systems with Applications 38(9): 11665-11670. http://dx.doi.org/10.1016/j.eswa.2011.03.046

Yue, Z. 2012a. Extension of TOPSIS to determine weight of decision maker for group decision making problems with uncertain information, Expert Systems with Applications 39(7): 6343-6350. http://dx.doi.org/10.1016/j.eswa.2011.12.016

Yue, Z. 2012b. Developing a straightforward approach for group decision making based on determining weights of decision makers, Applied Mathematical Modelling 36(9): 4106-4117. http://dx.doi.org/10.1016/j.apm.2011.11.041

Yue, Z. 2012c. Approach to group decision making based on determining the weights of experts by using projection method, Applied Mathematical Modelling 36(7): 2900-2910. http://dx.doi.org/10.1016/j.apm.2011.09.068

Yue, Z. 2014a. A group decision making approach based on aggregating interval data into intervalvalued intuitionistic fuzzy information, Applied Mathematical Modelling 38 (2): 683-698. http://dx.doi.org/10.1016/j.apm.2013.07.007 
Yue, Z. 2014b. Aggregating crisp values into intuitionistic fuzzy number for group decision making, Applied Mathematical Modelling 38(11-12): 2969-2982. http://dx.doi.org/10.1016/j.apm.2013.11.020

Zadeh, L. A. 1965. Fuzzy sets, Information and Control 8(3): 338-353. http://dx.doi.org/10.1016/S0019-9958(65)90241-X

Turskis, Z.; Zavadskas, E. K. 2010. A new fuzzy additive ratio assessment method (ARAS-F). Case study: the analysis of fuzzy multiple criteria in order to select the logistic centers location, Transport 25(4): 423-432. http://dx.doi.org/10.3846/transport.2010.52

Zavadskas, E. K.; Turskis, Z. 2011. Multiple Criteria Decision Making (MCDM) methods in economics: an overview, Technological and Economic Development of Economy 17(2): 397-427. http://dx.doi.org/10.3846/20294913. 2011.593291

Zavadskas, E. K.; Vilutienè, T.; Turskis, Z.; Šaparauskas, J. 2014a. Multi-criteria analysis of Projects' performance in construction, Archives of Civil and Mechanical Engineering 14(1): 114-121. http://dx.doi.org/10.1016/j.acme.2013.07.006

Zavadskas, E. K.; Turskis, Z.; Kildienė, S. 2014b. State of art surveys of overviews on MCDM/MADM methods, Technological and Economic Development of Economy 20(1): 165-179. http://dx.doi.org/10.3846/20294913.2014.892037

Zeleny, M. 1982. Multiple criteria decision making. New York: McGraw-Hill.

Zhou, L.; Chen, H.; Liu, J. 2013. Generalized multiple averaging operators and their applications to group decision making, Group Decision and Negotiation 22(2): 331-358. http://dx.doi.org/10.1007/s10726-011-9267-1

Zimmermann, H.-J. 1976. Description and optimization of fuzzy systems, International Journal General Systems 2: 209-215. http://dx.doi.org/10.1080/03081077608547470

Zimmermann, H.-J. 1987. Fuzzy sets, decision making, and expert systems. Boston: Kluwer.

Zimmermann, H.-J. 1991. Fuzzy set theory and its applications. 2nd ed. Boston: Kluwer Academic Publishers. http://dx.doi.org/10.1007/978-94-015-7949-0

Seyed Hossein RAZAVI HAJIAGHA. Assistant Professor at the Department of Management, Khatam Institute of Higher Education, Teheran, Iran. PhD in Production and Operation Management (2012). The author and co-author of about 20 scientific papers. Research interests: multi-criteria analysis, decision-making theories, data envelopment analysis and mathematical modelling of industrial problems.

Hannan Amoozad MAHDIRAJI. PhD in operation and manufacturing management from the University of Teheran, BA in industrial engineering. Assistant Professor of Kashan branch, Islamic Azad University and the Head of Planning and Systems Department of Iran Mercantile Exchange. Has published nearly 15 papers on supply chains and MCDM models in international journals and conferences.

Shide Sadat HASHEMI. MA in Production and Operation Management, researcher since 2009. Her research interests include operation management, multi-criteria decision making and data envelopment analysis. She is author and co-author of six scientific papers.

Zenonas TURSKIS. Professor, civil engineer, applied mathematics, PhD from VISI (Vilnius Engineering Construction Institute, former name of Vilnius Gediminas Technical University). He works at the Department of Construction Technology and Management of Vilnius Gediminas Technical University. He has more than 100 publications in journals such as International Journal of Information Technology \& Decision Making, Economic Research, Journal of Economic Computation and Economic Cybernetics Studies and Research (ECECSR) and more. His research interests include civil engineering, automated designing, programming, Operations Research methods in construction and economics, technological decisions in construction, decision support systems. 